\title{
Optimization of Process Parameters for Flux Cored Arc Welding of Boiler Quality Steel Using Response Surface Methodology and Grey-Based Taguchi Methods
}

\author{
Binoy Krishna Biswas, Pradip Kumar Pal, and Asish Bandyopadhyay
}

\begin{abstract}
To achieve weld of good quality and high deposition rate, it is essential to know about the influence of the welding parameters on the quality characteristics and deposition rate. It is thereby important to control the parameters accordingly. Process optimization is relevant in this contest. This is true for any welding process including flux cored arc welding (FCAW). In the present study metal plates of boiler quality (BQ) steel have been welded by FCAW at varied levels of input parameters. Input (welding) parameters have been considered in the study are: shielding gas $\left(\mathrm{CO}_{2}\right)$ flow rate, electrode wire feed rate and arc voltage. In the present work, the use of grey-based Taguchi method for multi-response optimization of the FCAW process in butt welding of $B Q$ steel is reported. Welding has been carried out using a semiautomatic GMAW welding setup on metal plates of BQ steel. Deposition rate has been selected as performance characteristic; hardness and percentage of elongation have been selected as quality characteristics. A regression model for these characteristics has been developed and its adequacy has been evaluated. A two order polynomial equation has been fitted to the data. Response surface methodology (RSM) has been applied to plot the three dimensional response surfaces for deposition rate, hardness and percentage of elongation with FCAW parameters. The importance of the welding parameters in respect of influence of these parameters on the quality index is determined by using analysis of variance (ANOVA).
\end{abstract}

Index Terms-ANOVA, boiler quality steel, FCAW, GMAW, grey-based Taguchi method, regression model, RSM.

\section{INTRODUCTION}

In FCAW process shielding of the molten weld pool, arc and adjacent area of base metal is obtained from the flux contained within the electrode [1]. To ease automation and reproducibility in FCAW, importance of process parameters in so far as their effects on the response characteristics need to be established reliably [2]. Boiler steel plate is a high quality steel, produced at the steel mill to a very high quality which is designed to withstand the internal pressure in boilers and valves. Boiler quality steel is a popular material due to its longevity and diversity of use. So for the present investigations boiler quality steel has been selected as parent material. During welding, the shielding gas protects and may also interact with the wire, depending on the type of gas used

Manuscript received October 9, 2014; revised June 12, 2015.

Binoy Krishna Biswas is with the Mechanical Engineering Department, B. P. Poddar Institute of Management and Technology, Kolkata, India (e-mail: binoy129@yahoo.com).

Pradip Kumar Pal and Asish Bandyopadhyay are with Jadavpur University, Kolkata, India (e-mail: pradippal54@yahoo.com, asishbanerjee@yahoo.com). to form a strong and tough corrosion-resistant weld. The shielding gas also affects the residual content of hydrogen, nitrogen and oxygen dissolved in the weld metal [3]. In the present experiments carbon dioxide flow rate has been used as one of the input parameters.

Vidala et al. [4], showed that during the tensile testing of weld joint, transverse welded specimens usually fail away from the weld joint. The results of such tests would inevitably provide base metal strength values but with reduced ductility, due to the presence of high strength zone within the gauge length. The objective of the parameter design is to optimize the settings of the process parameter values for improving performance characteristics and to identify the product parameter values under the optimal process parameter values. The parameter design is the key step in the Taguchi method to achieving high quality without increasing cost [5].

Gulhane et al. [6] studied the main effects using Taguchi method that indicated the general trend of influence of each parameter. Knowledge of the contribution of individual parameters is the key to deciding the nature of the control to be established on a production process. ANOVA can be useful for determining influence of any given input parameter for a series of experimental results by design of experiments for FCAW process and it can be used to interpret experimental data.

Literature reports that work has been done on various aspects of modelling, simulation and process optimization in the FCAW process on various metals but not so much on BQ. Arivazhagan et al. [7] studied the influence of shielding gas composition on toughness of flux-cored arc weld of modified $9 \mathrm{Cr}-1 \mathrm{Mo}$ (P91) steel. It was found that $95 \%$ argon $+5 \% \mathrm{CO} 2$ is the ideal shielding gas medium for FCAW process to meet the toughness requirements with better process characteristics; Sterjovski et al. [8] proposed Artificial Neural Network (ANN) for predicting diffusible hydrogen content and cracking susceptibility in rutile flux-cored arc welds. Kannan et al. [9] highlighted an experimental study carried out to analyze the effects of various flux cored arc welding (FCAW) process parameters on important clad quality parameters in duplex stainless steel cladding of low carbon structural steel plates; and Choi et al. [10] analyzed GMAW process by combining a finite element thermo-mechanical model for temperature and stress with solidification model. Model prediction was compared with experimental data in order to validate the model. Deng Chen et al. [11] proposed the integration of grey relational analysis and the Taguchi Method to resolve multiple quality characteristics.

To use FCAW to BQ steel efficiently and reliably, it is necessary to study joint properties. Hence, an attempt has 
been made in the present work to understand the effect of FCAW process parameters on percentage of elongation, hardness of fusion zone and deposition rate of boiler quality of steel. Multi objective process optimization has also been done by using grey-based Taguchi method.

\section{EXPERIMENTAL WORK}

Factorial Design of Operating Parameters: Taguchi based design of experiments has been used to study effect of three process parameters on the output responses. The working ranges of all the selected process parameters have been fixed by conducting trial runs. This has been carried out by varying one of the factors while keeping the rest of them at constant values. Within the selected range of the parameters the weld bead shows smooth appearance without any visible defects such as surface porosity, undercut, etc. Taguchi based L25 Orthogonal Array has been used to select five level three factor design matrix. Accordingly 25 experiments have been carried out. The process parameters and their levels are shown in Table I. The experimental layout using L25 Orthogonal Array and the corresponding values of predefined coded and uncoded controllable parameters are shown in Table II.

TABLE I: WELDING PARAMETERS AND THEIR LEVEL
\begin{tabular}{|c|c|c|c|}
\hline \multirow{3}{*}{ Level } & \multicolumn{3}{|c|}{ Factors } \\
\cline { 2 - 4 } & $\begin{array}{c}\text { Gas flow } \\
\text { rate }(G) \\
1 / \mathrm{min}\end{array}$ & $\begin{array}{c}\text { Wire feed } \\
\text { rate }(F) \\
\mathrm{m} / \mathrm{min}\end{array}$ & $\begin{array}{c}\text { Voltage } \\
(V) \\
\mathrm{V}\end{array}$ \\
\hline 1 & 5 & 6.05 & 28 \\
\hline 2 & 10 & 6.74 & 30 \\
\hline 3 & 15 & 7.43 & 32 \\
\hline 4 & 20 & 8.21 & 34 \\
\hline 5 & 25 & 8.94 & 36 \\
\hline
\end{tabular}

TABLE II: EXPERIMENTAL LAYOUT USING AN L25 (5^3) ORTHOGONAL

\begin{tabular}{|c|c|c|c|c|c|c|}
\hline \multicolumn{7}{|c|}{ ARRAY } \\
\hline \multirow[t]{2}{*}{ Sl No. } & \multicolumn{3}{|c|}{ Coded Parameter } & \multicolumn{3}{|c|}{ Uncoded Parameter } \\
\hline & $\mathrm{G}$ & $\mathrm{F}$ & $\mathrm{V}$ & $\begin{array}{c}\mathrm{G} \\
(1 / \mathrm{min})\end{array}$ & $\begin{array}{c}\mathrm{F} \\
(\mathrm{m} / \mathrm{min})\end{array}$ & $\begin{array}{c}\mathrm{V} \\
\text { (Voltage) }\end{array}$ \\
\hline 1 & 1 & 1 & 1 & 5 & 6.05 & 28 \\
\hline 2 & 1 & 2 & 2 & 5 & 6.74 & 30 \\
\hline 3 & 1 & 3 & 3 & 5 & 7.42 & 32 \\
\hline 4 & 1 & 4 & 4 & 5 & 8.21 & 34 \\
\hline 5 & 1 & 5 & 5 & 5 & 8.94 & 36 \\
\hline 6 & 2 & 1 & 2 & 10 & 6.05 & 30 \\
\hline 7 & 2 & 2 & 3 & 10 & 6.74 & 32 \\
\hline 8 & 2 & 3 & 4 & 10 & 7.42 & 34 \\
\hline 9 & 2 & 4 & 5 & 10 & 8.21 & 36 \\
\hline 10 & 2 & 5 & 1 & 10 & 8.94 & 28 \\
\hline 11 & 3 & 1 & 3 & 15 & 6.05 & 32 \\
\hline 12 & 3 & 2 & 4 & 15 & 6.74 & 34 \\
\hline 13 & 3 & 3 & 5 & 15 & 7.42 & 36 \\
\hline 14 & 3 & 4 & 1 & 15 & 8.21 & 28 \\
\hline 15 & 3 & 5 & 2 & 15 & 8.94 & 30 \\
\hline 16 & 4 & 1 & 4 & 20 & 6.05 & 34 \\
\hline 17 & 4 & 2 & 5 & 20 & 6.74 & 36 \\
\hline 18 & 4 & 3 & 1 & 20 & 7.42 & 28 \\
\hline 19 & 4 & 4 & 2 & 20 & 8.21 & 30 \\
\hline 20 & 4 & 5 & 3 & 20 & 8.94 & 32 \\
\hline 21 & 5 & 1 & 5 & 25 & 6.05 & 36 \\
\hline 22 & 5 & 2 & 1 & 25 & 6.74 & 28 \\
\hline 23 & 5 & 3 & 2 & 25 & 7.42 & 30 \\
\hline 24 & 5 & 4 & 3 & 25 & 8.21 & 32 \\
\hline 25 & 5 & 5 & 4 & 25 & 8.94 & 34 \\
\hline
\end{tabular}

Work Material and FCAW Electrode Material: Boiler quality steel (IS 2002:92/Gr II) plates with the dimensions of $100 \times 50 \times 12 \mathrm{~mm}$ are prepared with the bevel angle of $30^{\circ}$. Basic Flux cored wire (AWS specification, E 71 T-1) with 1.2 $\mathrm{mm}$ diameter has been used throughout the experimental work. Chemical compositions of the work piece material and the electrode material used in this study are given in the Table III.

TABLE III: CHEMICAL COMPOSITIONS OF BQ STEEL AND FCAW ELECTRODE

\begin{tabular}{|c|c|c|c|c|}
\hline \multicolumn{5}{|c|}{ Parent metal } \\
\hline$\% \mathrm{C}$ & $\% \mathrm{Mn}$ & $\% \mathrm{Si}$ & $\% \mathrm{~S}$ & $\% \mathrm{P}$ \\
\hline 0.19 & 0.94 & 0.23 & 0.026 & 0.035 \\
\hline \multicolumn{5}{|c|}{ Electrode } \\
\hline$\% \mathrm{C}$ & $\% \mathrm{Mn}$ & $\% \mathrm{Si}$ & $\% \mathrm{~S}$ & $\% \mathrm{P}$ \\
\hline 0.05 & 1.00 & 0.74 & 0.05 & 0.008 \\
\hline
\end{tabular}

Experimental Procedure: All the butt welds have been conducted with $60^{\circ}$ single $\mathrm{V}$ edge preparation. The ' $\mathrm{V}$ ' groove angle (30degree) has been cut in each of the plates and then plates have been set with $3 \mathrm{~mm}$ root faces and $3 \mathrm{~mm}$ root distance for a total of 60 degree inclined angle between two plates. The geometry of the groove design is shown in Fig. 1. Welding torch angle with reference to horizontal have been maintained manually within $55^{\circ}-60^{\circ}$.

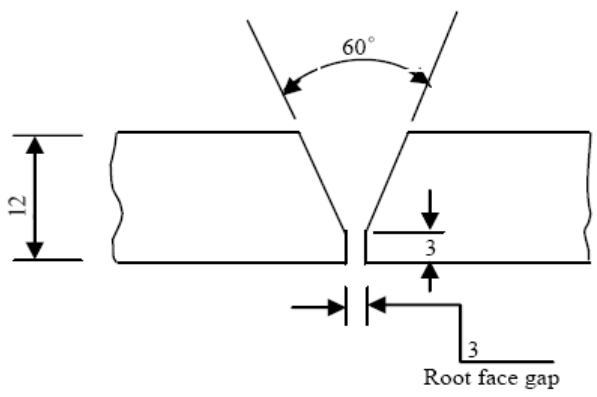

Fig. 1. Groove geometry of test plates.

The welding test has been conducted using a semiautomatic GMAW machine. It is done by multilayer and multi-pass welding process. The number of runs in each case is same. The wire is automatically fed through the centre of the gun of the machine and the shielding gas has been supplied through the gun.

After welding of 25 samples, tensile test specimens have been prepared by cutting and machining. The size and shape of each tensile test specimen is shown in Fig. 2.

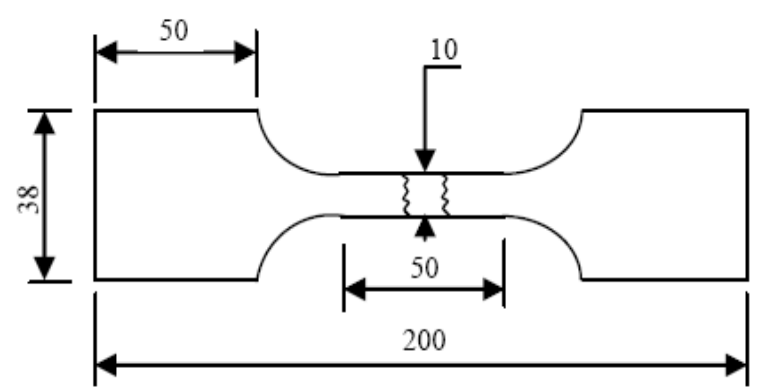

Fig. 2. Tensile test specimen geometry.

Small cut-outs have been taken from the butt-welded samples, for preparing specimens for hardness test of the weldment. For making these specimens, the cut outs has been first ground and then polished with several grades of emery 
papers sequentially (from coarse to finer grades) and etched with $2 \%$ Nital solution to reveal fusion zone (FZ) clearly.

Hardness has been measured by LEICA Vickers Micro-hardness Hardness Tester (VMHT) with 100g load. Measurement has been taken at different locations in the FZ (Fig. 3). After etching the surface, indentations have been made at $1 \mathrm{~mm}$ spacing across the area of the weldment at a depth of $2 \mathrm{~mm}$ from the top surface of the weld. In some regions measurements have been made at closer space intervals.

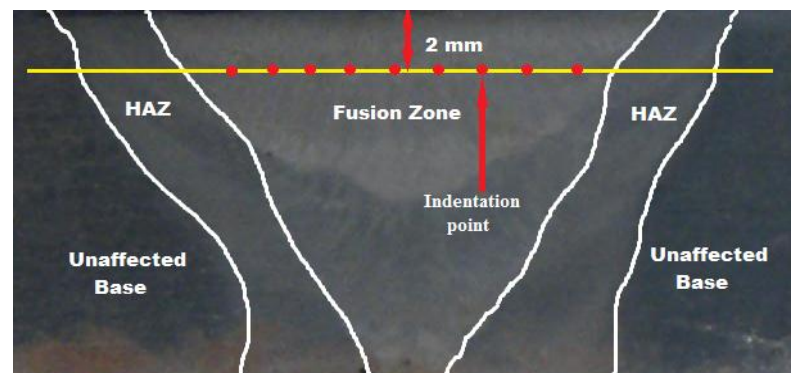

Fig. 3. Macro photographs of the weld cross-sections after etching showing $\mathrm{HAZ}$ and $\mathrm{FZ}$.

\section{GREY RELATIONAL ANALYSIS (GRA)}

In Grey relational analysis, experimental data i.e., measured features of quality characteristics are first normalized so that each of the data ranges from 0 to 1 . This process is known as grey relational generation. Next, based on normalized experimental data, grey relational coefficient is calculated to represent the correlation between the desired and actual experimental data. Then overall grey relational grade is determined by averaging the grey relational coefficient corresponding to selected responses. The overall performance characteristic of the multiple response process depends on the calculated grey relational grade. The optimal parametric combination is then evaluated which would result highest grey relational grade. The optimal factor setting for maximizing overall grey relational grade can be performed by Taguchi method [12], [13]. The proposed procedure for solving the multiple response problems is described in the following steps:

- Step 1: For each experiment in the orthogonal array, the value of the $j$ th response, $y_{i j}$, for $i$ th experiment is to be obtained.

- Step 2: Grey relational generation: Normalized value $x_{i j}$ ranging from 0 to 1 of the response $y_{i j}$ is to be calculated using (1) or (2). Equation (1) holds well for the larger the better response like deposition rate and percentage of elongation.

$$
x_{i j}=\frac{y_{i j}-\min y_{i j}}{\max y_{i j}-\min y_{i j}}
$$

For smaller-the-better responses like hardness normalized values of the responses is determined by (2).

$$
x_{i j}=\frac{\max y_{i j}-y_{i j}}{\max y_{i j}-\min y_{i j}}
$$

- Step 3: The Grey relational coefficient (GRC) for $j^{\text {th }}$ response, $\xi_{i j}$ is to be calculated as:

$$
\xi_{i j}=\frac{\Delta_{\min }+\psi \Delta_{\max }}{\Delta_{0 i j}+\psi \Delta_{\max }}
$$

where $\Delta_{0 i j}=\left|x_{0 j}-x_{i j}\right|=$ difference of the absolute value between ideal setting $x_{0 j}$ (usually is equals to 1 ) and $x_{i j}$; $\psi$ is the distinguishing coefficient which ranges between zero and one; usually $\psi$ equals 0.5 .

$\Delta_{\min }$ and $\Delta_{\max }$ are the smallest and largest value of $\Delta_{0 i j}$ respectively.

- Step 4: If grey relational grade (GRD) is denoted by $g_{i}$ for the $i$ th experiment from all 3 responses then $g_{i}$ is calculated using (4).

$$
g_{i}=\frac{1}{3} \sum_{j=1}^{3} \xi_{i j}
$$

- Step 5: The obtained data for $g_{i}$ are used to get optimum level of parameters through Taguchi approach.

$\mathrm{S} / \mathrm{N}$ ratio refers to signal to noise ratio that is used to measure the quality characteristic deviating from the desired value. Regardless of the category of the responses, a greater $\mathrm{S} / \mathrm{N}$ ratio corresponds to better quality characteristics. Therefore, the optimal level of the process parameters is the level with the greatest $\mathrm{S} / \mathrm{N}$ ratio.

Based on the desired characteristic of output parameters two important $\mathrm{S} / \mathrm{N}$ ratios $(\eta)$ of the response ' $y$ ' are formulated as follows:

- Smaller the better characteristic:

If the smaller values of the output characteristics are desirable then,

$$
\eta=-10 \log \left((1 / n)\left(\sum y^{2}\right)\right)
$$

- Larger the better characteristic:

If the larger values of the output characteristics are desirable then,

$$
\eta=-10 \log \left((1 / n)\left(\sum\left(1 / y^{2}\right)\right)\right.
$$

\section{RESUlTS AND DISCUSSION}

\section{A. Optimization of Operating Parameters}

Weight of the joining plates has been measured prior to welding $\left(W_{p}\right)$. Using a stop watch the total time $(t)$ for welding has been recorded. Weight of the specimen after joining $\left(W_{f}\right)$ has been measured by electronic weighing machine. Deposition rate $(D)$ is calculated using (7).

$$
D=\frac{W_{f}-W_{p}}{t}
$$

In FCAW, lower FZ hardness; higher deposition rate and higher percentage of elongation (EL) are the indications of 
better performance. For data pre-processing in the grey relational analysis process, FZ hardness is taken as the 'smaller the better', deposition rate and percentage of elongation are taken as the 'larger the better'. Initially, normalised value for deposition rate and percentage of elongation are computed using (1) and those of FZ hardness are computed using (2). Substituting these values in (3), Grey relational coefficients (GRC) are computed. The results thus obtained are listed in Table IV and Table V.

TABLE IV: COMPUTED VALUE AND CORRESPONDING GREY RELATION COEFFICIENT FOR DEPOSITION RATE AND PERCENTAGE OF ELONGATION

\begin{tabular}{|c|c|c|c|c|}
\hline \multirow[b]{2}{*}{$\begin{array}{l}\text { S1. } \\
\text { No }\end{array}$} & \multicolumn{2}{|c|}{ Deposition rate } & \multicolumn{2}{|c|}{$\begin{array}{c}\text { Percentage of Elongation } \\
\text { (EL) }\end{array}$} \\
\hline & $\begin{array}{l}\text { Computed } \\
\text { Value } \\
\text { (D) } \\
(\mathrm{g} / \mathrm{s})\end{array}$ & $\begin{array}{l}\mathrm{GRC} \\
\xi_{i z}\end{array}$ & $\begin{array}{l}\text { Computed } \\
\text { Value }\end{array}$ & $\begin{array}{c}\text { GRC } \\
\xi_{i z}\end{array}$ \\
\hline 1 & 0.623 & 0.488692 & 30.9 & 0.625468 \\
\hline 2 & 0.386 & 0.333333 & 33.3 & 0.762557 \\
\hline 3 & 0.668 & 0.536138 & 26.3 & 0.465181 \\
\hline 4 & 0.665 & 0.53269 & 24.8 & 0.429306 \\
\hline 5 & 0.749 & 0.649673 & 22.8 & 0.389277 \\
\hline 6 & 0.587 & 0.456382 & 29.0 & 0.547541 \\
\hline 7 & 0.606 & 0.472883 & 28.0 & 0.513846 \\
\hline 8 & 0.692 & 0.565415 & 27.8 & 0.507599 \\
\hline 9 & 0.732 & 0.622028 & 33.5 & 0.776744 \\
\hline 10 & 0.883 & 1 & 27.6 & 0.501502 \\
\hline 11 & 0.670 & 0.538462 & 33.6 & 0.784038 \\
\hline 12 & 0.639 & 0.504569 & 27.7 & 0.504532 \\
\hline 13 & 0.655 & 0.521511 & 30.2 & 0.594306 \\
\hline 14 & 0.746 & 0.644617 & 30.0 & 0.585965 \\
\hline 15 & 0.819 & 0.79520 & 19.2 & 0.333333 \\
\hline 16 & 0.565 & 0.438658 & 29.9 & 0.581882 \\
\hline 17 & 0.581 & 0.451408 & 35.9 & 1 \\
\hline 18 & 0.681 & 0.551609 & 31.3 & 0.644788 \\
\hline 19 & 0.753 & 0.656539 & 30.1 & 0.590106 \\
\hline 20 & 0.811 & 0.775351 & 27.9 & 0.510703 \\
\hline 21 & 0.571 & 0.443354 & 26.0 & 0.457534 \\
\hline 22 & 0.818 & 0.792663 & 30.4 & 0.602888 \\
\hline 23 & 0.667 & 0.534984 & 26.9 & 0.481268 \\
\hline 24 & 0.617 & 0.482993 & 29.1 & 0.551155 \\
\hline 25 & 0.843 & 0.861352 & 30.3 & 0.598566 \\
\hline
\end{tabular}

Substituting the values of $\xi_{i j}$ from Table IV and Table V in (4) Grey relational grade (GRD) is determined. Hence optimization of the complicated multiple performance characteristics is converted into the optimization of a single characteristic i.e. Grey relational grade. A higher Grey relational grade indicates that the corresponding $\mathrm{S} / \mathrm{N}$ ratio is closer to the ideally normalized $\mathrm{S} / \mathrm{N}$ ratio. $\mathrm{S} / \mathrm{N}$ ratio of GRD of all the experiment is calculated using (6).

The effect of each welding process parameter on the S/N ratio at different levels can be separated out because the experimental design is orthogonal. The obtained $\mathrm{S} / \mathrm{N}$ ratio is employed here to calculate the average $\mathrm{S} / \mathrm{N}$ ratio for each welding process parameter level. It is done by sorting the $\mathrm{S} / \mathrm{N}$ ratio corresponding to levels of the welding parameter in each column of the orthogonal array, and taking an average on those with the same level [14]. Using the same method, calculations are performed and the results of these calculations are in Table VI.

The optimum parameter setting is: G2F2V5 (i.e. shielding gas flow rate at level 2 or $10 \mathrm{l} / \mathrm{min}$; wire feed rate at level 2 or $6.74 \mathrm{~m} / \mathrm{min}$ and voltage at level 5 or $36 \mathrm{~V}$ ). Basically, larger the $\mathrm{S} / \mathrm{N}$ ratio is better the corresponding multiple performance characteristic. These data are also plotted in Fig. 4. * Values in Table VI signify the optimum level based on the larger the better criterion.
TABLE V: COMPUTED VALUE AND CORRESPONDING GREY RELATION COEFFICIENT FOR MICRO-HARDNESS OF FZ AND OVERALL GREY RELATIONAL GRADE

\begin{tabular}{|c|c|c|c|}
\hline \multirow{2}{*}{$\begin{array}{l}\text { Sl. } \\
\text { No }\end{array}$} & \multicolumn{2}{|c|}{ Micro-Hardness of FZ } & \multirow{2}{*}{$\begin{array}{c}\text { Grey } \\
\text { Relational } \\
\text { Grade } \\
\text { (GRD) }\end{array}$} \\
\hline & $\begin{array}{c}\text { Computed } \\
\text { Value } \\
\text { (HV) }\end{array}$ & $\begin{array}{c}\text { GRC } \\
\xi_{i z}\end{array}$ & \\
\hline 1 & 334.6 & 0.44429 & 0.51948 \\
\hline 2 & 240.8 & 0.78449 & 0.62679 \\
\hline 3 & 253.2 & 0.71238 & 0.57123 \\
\hline 4 & 216.4 & 0.979613 & 0.64720 \\
\hline 5 & 250.9 & 0.724736 & 0.58789 \\
\hline 6 & 223.2 & 0.916111 & 0.64001 \\
\hline 7 & 214.4 & 1 & 0.66224 \\
\hline 8 & 228.7 & 0.870471 & 0.64783 \\
\hline 9 & 255.0 & 0.702999 & 0.70059 \\
\hline 10 & 317.1 & 0.4834 & 0.66163 \\
\hline 11 & 291.7 & 0.55421 & 0.62557 \\
\hline 12 & 236.9 & 0.810287 & 0.60646 \\
\hline 13 & 227.7 & 0.878428 & 0.66475 \\
\hline 14 & 296.8 & 0.538375 & 0.58965 \\
\hline 15 & 292.0 & 0.553253 & 0.56059 \\
\hline 16 & 250.1 & 0.729135 & 0.58322 \\
\hline 17 & 216.4 & 0.979613 & 0.81034 \\
\hline 18 & 225.9 & 0.893123 & 0.69651 \\
\hline 19 & 255.8 & 0.698909 & 0.64852 \\
\hline 20 & 326.7 & 0.461132 & 0.58239 \\
\hline 21 & 224.3 & 0.906604 & 0.51948 \\
\hline 22 & 259.2 & 0.682044 & 0.62679 \\
\hline 23 & 268.1 & 0.641522 & 0.57123 \\
\hline 24 & 406.6 & 0.333333 & 0.64720 \\
\hline 25 & 257.5 & 0.690374 & 0.58789 \\
\hline
\end{tabular}

TABLE VI: AVERAGE S/N RATIO VALUES OF GRD AT DIFFERENT LEVEL OF THE WELDING PARAMETER

\begin{tabular}{|c|c|c|c|}
\hline $\begin{array}{c}\text { Level } \\
\text { level }\end{array}$ & $\begin{array}{c}\mathrm{G} \\
(1 / \mathrm{min})\end{array}$ & $\begin{array}{c}\mathrm{F} \\
(\mathrm{m} / \mathrm{min})\end{array}$ & $\begin{array}{c}\mathrm{V} \\
(\text { Voltage })\end{array}$ \\
\hline 1 & -4.60 & -4.545 & -4.039 \\
\hline 2 & $-3.581^{*}$ & $-3.400^{*}$ & -4.375 \\
\hline 3 & -4.316 & -4.095 & -4.808 \\
\hline 4 & -3.622 & -4.409 & -3.894 \\
\hline 5 & -4.492 & -4.163 & $-3.496^{*}$ \\
\hline
\end{tabular}

* Corresponds to optimum condition

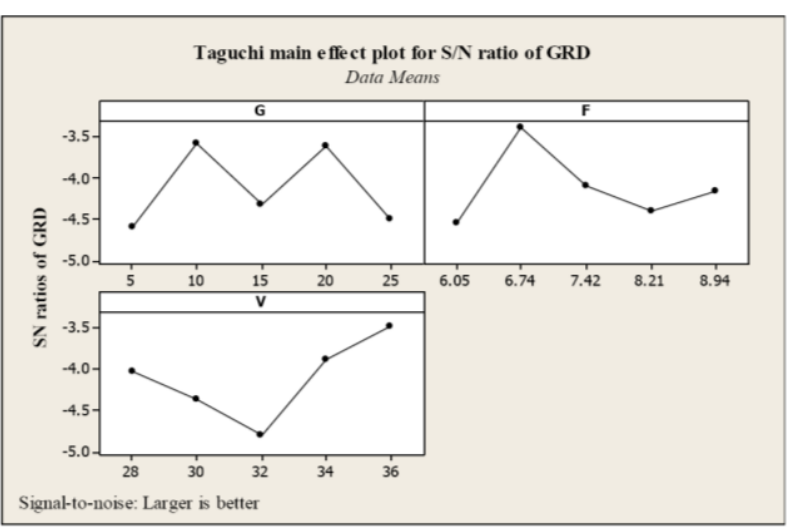

Fig. 4. S/N ratio plots for GRD.

\section{B. Analysis of Variance}

The relative importance of the welding process parameters for the multiple performance characteristic can be identified by analysis of variance (ANOVA).

The analysis is accomplished by separating the total variability of the grey relational grades, (which is measured by the sum of the squared deviations from the total mean of the grey relational grade) into contributions by each welding process parameter and the error. The percentage contribution by each of the process parameter in the total sum of the squared deviations can be used to evaluate the importance of the process parameter change on the performance characteristic. In addition, the $F$-test named after Fisher [15] 
can also be used to determine welding process parameter that significantly effect on the response characteristic.

Usually, the change of the welding process parameter has a significant effect on the output or response characteristic when the $F$ value is large. Probability $(P)$ values are determined at $95 \%$ significance level; if $P$-values are less than 0.05 then the corresponding parameter is considered to be significant as $95 \%$ confidence level.

An informal interpretation of a $P$-value [16], based on a significance level of about $10 \%$, might be:

TABLE VII: RESULTS OF ANALYSIS OF VARIANCE FOR THE RESPONSES AND GRD

\begin{tabular}{|c|c|c|c|c|c|c|c|}
\hline Response & Symbol & $\begin{array}{c}\text { Process } \\
\text { parameter }\end{array}$ & $\begin{array}{c}\text { Degrees of } \\
\text { freedom }\end{array}$ & $\begin{array}{l}\text { Sum of } \\
\text { squares }\end{array}$ & $F$ & $P$ value & $\begin{array}{c}\text { Contribution } \\
\text { Percentage }\end{array}$ \\
\hline \multirow{5}{*}{ Deposition Rate } & $G$ & Gas flow rate & 4 & 0.027103 & 1.24 & 0.346 & 09.5 \\
\hline & $F$ & Wire feed rate & 4 & 0.159075 & 7.27 & 0.003 & 55.6 \\
\hline & $V$ & voltage & 4 & 0.034349 & 1.57 & 0.245 & 12.0 \\
\hline & Error & & 12 & 0.065674 & & & 27.1 \\
\hline & Total & & 24 & 0.286200 & & & \\
\hline \multirow{5}{*}{$\begin{array}{l}\text { Percentage of } \\
\text { Elongation }\end{array}$} & $G$ & Gas flow rate & 4 & 3459 & 064 & 0646 & 113 \\
\hline & $F$ & Wire feed rate & 4 & 86.51 & 2.17 & 0.098 & 28.4 \\
\hline & $V$ & voltage & 4 & 19.97 & 2.79 & 0.075 & 6.5 \\
\hline & Error & & 12 & 163.33 & & & \\
\hline & Total & & 24 & 304.40 & & & \\
\hline & & & & & & & \\
\hline \multirow{5}{*}{ Micro-Hardness } & $G$ & Gas flow rate & 4 & 3776 & 0.64 & 0.646 & 7.4 \\
\hline & $F$ & Wire feed rate & 4 & 12847 & 2.18 & 0.093 & 25.2 \\
\hline & $V$ & voltage & 4 & 16471 & 2.78 & 0.076 & 43.2 \\
\hline & Error & & 12 & 17798 & & & \\
\hline & Total & & 24 & 50893 & & & \\
\hline
\end{tabular}

- $p \leq 0.01$ : very strong presumption against null hypothesis;

- $0.01<p \leq 0.05$ : strong presumption against null hypothesis;

- $0.05<p \leq 0.1$ : low presumption against null hypothesis;

- $p>0.1$ : no presumption against the null hypothesis.

Results of ANOVA (Table VII) indicate that wire feed rate is the most significant ( $P$-value 0.03 ) welding process parameter influencing the deposition rate. The high $F$ value (7.27) and high percentage of contribution (55.6\%) also describes the significance of wire feed rate on deposition rate. In case of percentage of elongation and micro-hardness of fusion zone $P$-values against wire feed rate are 0.098 and 0.093 respectively. These values describe low presumption against null hypothesis. Voltage also has significant effect on percentage of elongation and micro-hardness of fusion zone ( $P$-values are 0.075 and 0.076 respectively). Effect of shielding gas flow rate on the responses indicates no presumption against the null hypothesis.

\section{Residual Analysis}

Residual or error analysis is a good idea to assess the validity of the model. Residual plots are representatives of the function of the difference between observed responses and those predicted by the model. For a good modeling residuals or error terms should be normally or randomly distributed. The non-random pattern in the residuals indicates that the deterministic portion of the model is not capturing some explanatory information that is "leaking" into the residuals. The graph could represent several ways in which the model is not explaining all that is possible. Possibilities include:

- A missing variable;

- A missing higher-order term of a variable in the model to explain the curvature;

- A missing interaction between terms, already in the model.

Identifying and fixing the problem so that the deterministic portion now explains the information that they missed before should produce a good-looking set of residuals. The residual plots for GRD are shown in Fig. 5.

In normal probability plot the red dots are close to the blue line of expected values. It indicates that the residual or error terms are in acceptable normal distribution. Shape resembling an almost regular distribution in the histogram is satisfactory. The residuals versus fitted values should just show random scatter. Mild deviations from the ideal pattern are not too alarming. However, major deviations will suggest that the model is unreliable. This may require further analysis and discussion which can be taken up in some subsequent report. Here in Fig. 5 fitted values are in random scatter. The observation order graph is only useful if the order of observations in the dataset has some meaning, for example, if the data were collected over a period of time in this order.

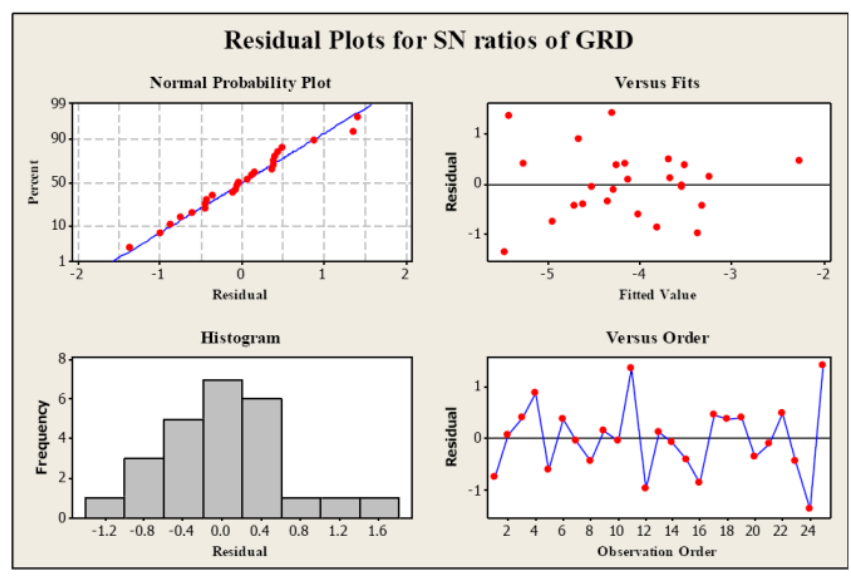

Fig. 5. Residual plots for GRD.

\section{Response Surface Modeling}

RSM has been used to plot the response vs. controllable parameter. It is a collection of mathematical and statistical techniques in which a response of interest is influenced by several variables and the objective is to optimize this response. The second goal is to understand how the response changes in 
a given direction by adjusting the design variables. In general, the response surface can be visualized graphically [17]-[21]. In this work optimization has been done through Taguchi method, so RSM has been used only to plot response surface.The graph is helpful to see the shape of a response surface; hills, valleys, and ridge lines. The nonlinear quadratic model has been generated by the design of the formula:

$$
\begin{aligned}
& \eta=\beta_{0}+\beta_{1} x_{1}+\beta_{2} x_{2}+\beta_{3} x_{3}+\beta_{11} x_{1}^{2}+\beta_{22} x_{2}^{2} \\
& +\beta_{33} x_{3}^{2}+\beta_{12} x_{1} x_{2}+\beta_{23} x_{2} x_{3}+\beta_{31} x_{3} x_{1}
\end{aligned}
$$

It can also be represented as

$$
\eta=\beta_{0}+\sum_{i=1}^{k} \beta_{i} x_{i}+\sum_{i=1}^{k} \beta_{i i} x_{i}^{2}+\sum_{j<} \sum_{i=2}^{k} \beta_{i j} x_{i} x_{j}(9)
$$

where $\beta_{0}, \beta_{i}, \beta_{i i}$ and $\beta_{i j}$ are the regression coefficients of intercept, linear, quadratic and interaction variables respectively, $\eta$ is the dependent variable or the response, $x_{i}$ independent parameter is often called predictor variable or regressor in uncoded unit, this can be one of $G, F$ or $V . k$ is the number of controllable parameter or input parameter; here $k=$ 3 . In this study regression coefficients were computed by statistical software package MINITAB 15 . The full quadratic model of the responses has been obtained using these regression coefficients. These are given in (10), (11) and (12), respectively.

$$
\begin{aligned}
& D=6.36246+0.24900 G+0.26636 F-0.62664 V \\
& +0.00720 G^{2}+0.41434 F^{2}+0.05040 V^{2}+0.10323 G F^{(10)} \\
& -0.03968 G V-0.25696 F V
\end{aligned}
$$

$$
\begin{aligned}
& E L=222.448-3.496 G-3.458 F-8.635 V-0.102 G^{2} \\
& -5.224 F^{2}-0.338 V^{2}-0.949 G F+0.443 G V+3.050 F V \\
& H V=1024.56+5.08 G-70.11 F-43.76 V+1.09 G^{2} \\
& +58.74 F^{2}+5.63 V^{2}+14 G F-4.5514 G V-32.41 F V
\end{aligned}
$$

The response function $R(R=f(G, F, V))$ can be plotted against the levels of $G, F$ and $V$ as shown in the following figures (Fig. 6-Fig. 14). In these graphs, any two of three process parameter generates an $R$-value, where the third value is set constant at any particular level. This three-dimensional graph shows the response surface and it is called a response surface plot. Sometimes, it is less complicated to view the response surface in two-dimensional graphs termed as contour plot. Response function $R$ is the function of three variables, hence to generate three dimensional surface plots one of the parameters value is to set at predefined value. In the present plots the values of the third factors is set at its middle value.

The 3D surface plots and 2D contour plots are plotted considering the Taguchi design matrix and using the software MINITAB 15.

In Fig. 6, the three-dimensional surface plot and two dimensional contour plots are displayed according to (10).
The graph determined the contribution of the shielding gas flow rate and wire feed rate on weld metal deposition rate. The response is at its highest at the darkest region (bottom left corner) of the graph. The figure has been drawn considering the hold value of voltage at $32 \mathrm{~V}$. It is observed that deposition rate is higher when wire feed rate is set at a lowest value (6.05 $\mathrm{m} / \mathrm{min}$ ) and gas flow rate is also set at a lowest value ( $5 \mathrm{l} / \mathrm{min})$.

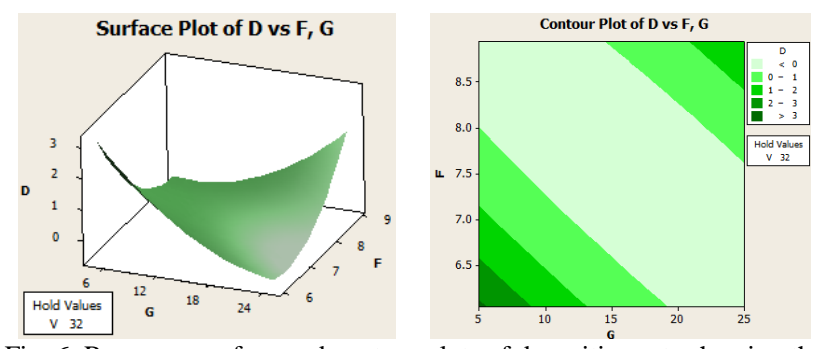

Fig. 6. Response surface and contour plots of deposition rate showing the combined effects of wire feed rate and gas flow rate.

In Fig. 7, the three-dimensional surface plot and two dimensional contour plots are displayed according to Eq. (10). The graph has shown the contribution of the shielding gas flow rate and voltage on weld pool deposition rate. The response is at its highest at the top left corner of the graph. The figure has been drawn considering the hold value of wire feed rate at $7.43 \mathrm{~m} / \mathrm{min}$. It is observed that deposition rate is higher when wire feed rate is set at a lowest value $(6.05 \mathrm{~m} / \mathrm{min})$ and voltage is also set at a highest value $(36 \mathrm{~V})$.

Fig. 8 describes the effect of wire feed rate and voltage on weld pool deposition rate when gas flow rate has been fixed at $15 \mathrm{l} / \mathrm{min}$. Both the surface and contour plots are drawn based on a regression Eq. (10). The darkest region is at the left top corner of the contour plot. The response is maximum as wire feed rate is minimum $(6.05 \mathrm{~m} / \mathrm{min})$ and voltage maximum $(36 \mathrm{~V})$.
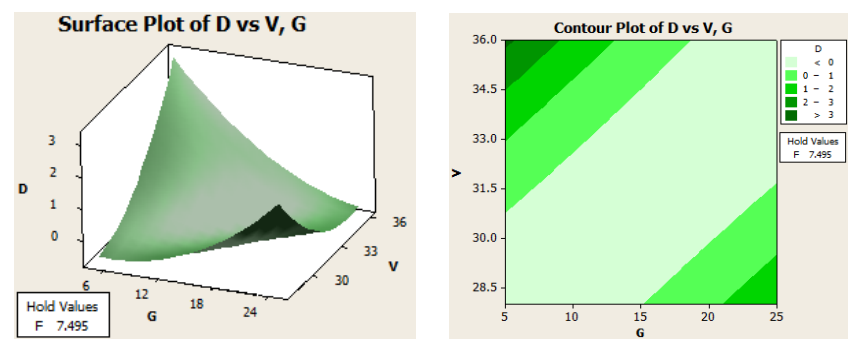

Fig. 7. Response surface and contour plots of deposition rate showing the combined effects of voltage and gas flow rate.
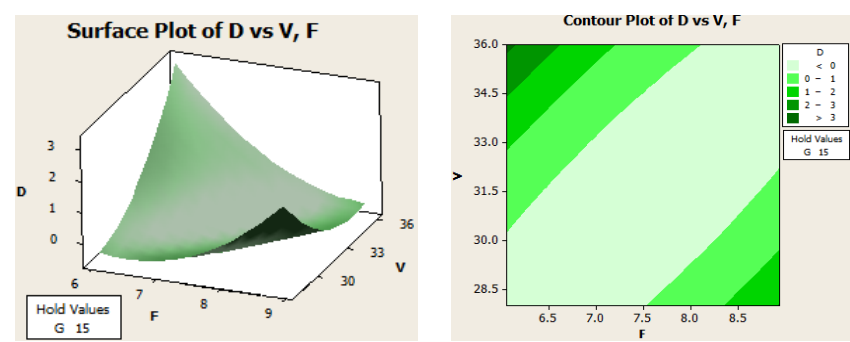

Fig. 8. Response surface and contour plots of deposition rate showing the combined effects of wire feed rate and voltage.

Fig. 9 depicts the combined effect of wire feed rate and shielding gas flow rate on percentage of elongation at a voltage $32 \mathrm{~V}$ based on Eq. (11). The following 3D surface and contour plots represent a response surface with a simple 
maximum [22]. As the color gets darker, the response increases. It is observed from the plots that percentage of elongation is higher if wire feed rate and gas flow rate are kept at around $7.5 \mathrm{~m} / \mathrm{min}$ and $17 \mathrm{~m} / \mathrm{min}$ respectively. It is found from both of the plots that the interaction effects of shielding gas flow rate and wire feed rate is highly significant.
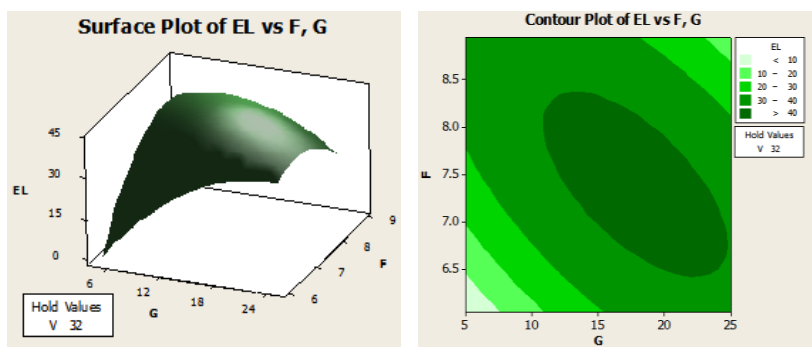

Fig. 9. Response surface and contour plots of percentage of elongation $(E L)$ showing the combined effects of wire feed rate and gas flow rate.

In Fig. 10, the three-dimensional surface plot and two dimensional contour plots are displayed according to (11), when hold value of voltage is $32 \mathrm{~V}$. The following $3 \mathrm{D}$ surface and contour plots represent a stationary ridge surface [22]. As the color gets darker, the response increases. A stationary ridge is shaped like an arch. The interaction effects are significant but, there are many possible factors settings that maximize the response.

The same have been observed in Fig. 11 that describes the combined effect of voltage and wire feed rate at hold value $(7.43 \mathrm{~m} / \mathrm{min})$ of shielding gas flow rate. These plots are also developed on the basis of (11).

The same have been observed in Fig. 11 that describes the combined effect of voltage and wire feed rate at hold value $(7.43 \mathrm{~m} / \mathrm{min})$ of shielding gas flow rate. These plots are also developed on the basis of (11).
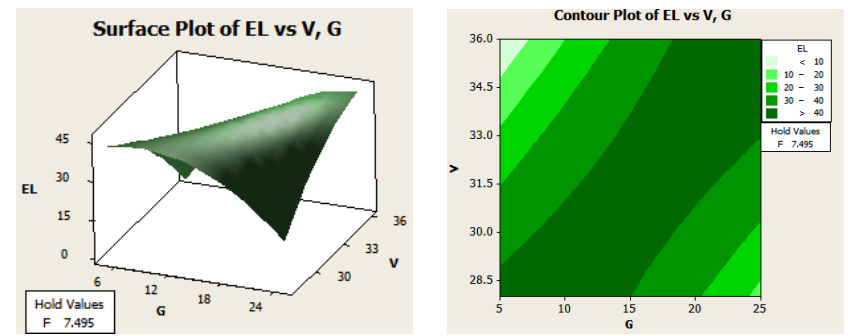

Fig. 10. Response surface and contour plots of percentage of elongation $(E L)$ showing the combined effects of voltage and gas flow rate.
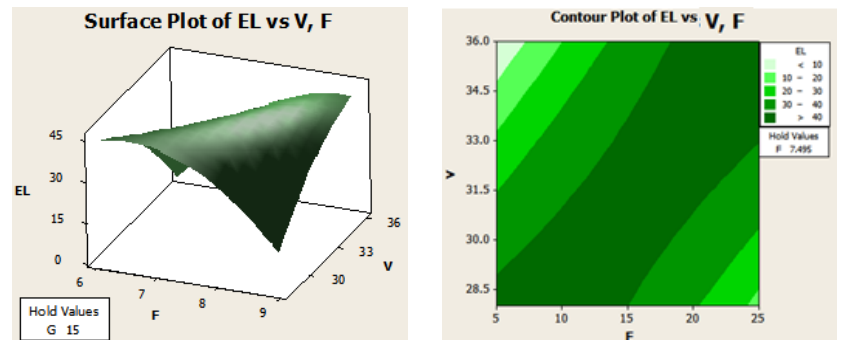

Fig. 11. Response surface and contour plots of percentage of elongation (EL) showing the combined effects of voltage and wire feed rate.

As shown in Fig. 12, Fig. 13 and Fig. 14 the interaction effects are insignificant. The plots reveal that the color gets darker at two opposite corners of the contour plots and the areas are small and so it indicates the insignificant interaction effect. The plots have been drawn based on the (12). It is also observed that there is no combined effect of the welding properties on fusion zone of weldment. The above three figures (Fig. 12-Fig. 14) have been plotted considering hold value of $32 \mathrm{~V}$ for Fig. 12, wire feed rate $7.495 \mathrm{~m} / \mathrm{min}$ for Fig. 13 and gas flow rate of 15 l/min for Fig. 14 respectively.
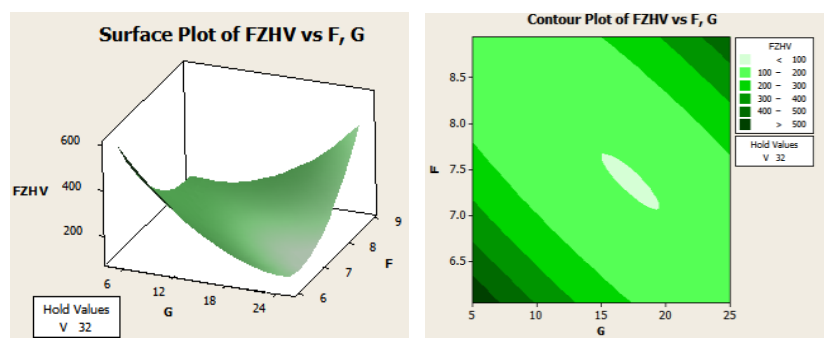

Fig. 12. Response surface and contour plots of fusion zone hardness $\left(\mathrm{H}_{2}\right)$ showing the combined effects of wire feed rate and gas flow rate.
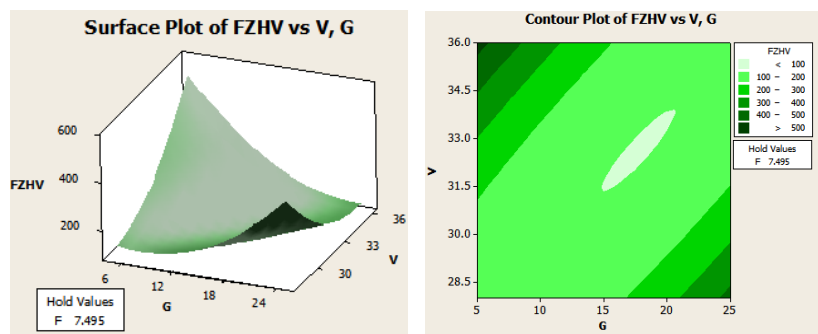

Fig. 13. Response surface and contour plots of fusion zone hardness $\left(H_{2}\right)$ showing the combined effects of voltage and gas flow rate.
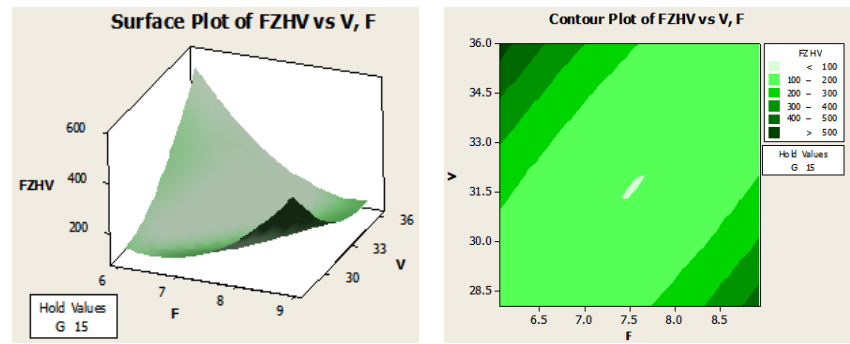

Fig. 14. Response surface and contour plots of fusion zone hardness (FZHV) showing the combined effects of voltage and wire feed rate.

\section{E. Microstructure}

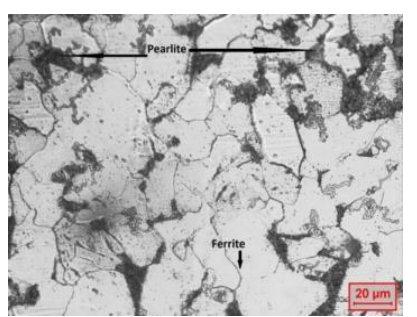

(a)

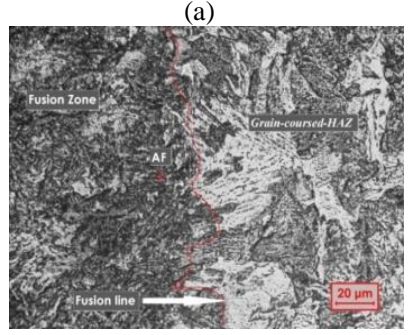

(c)

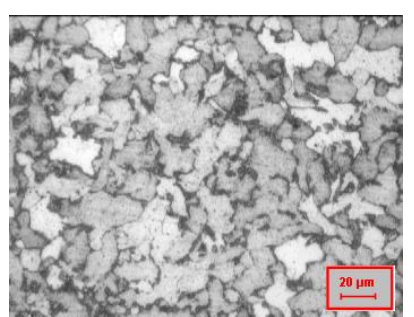

(b)

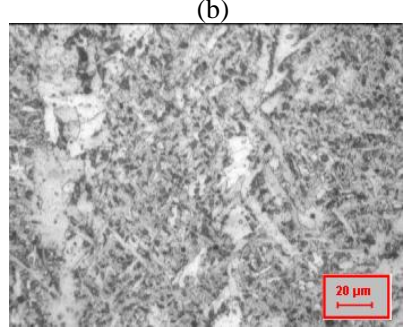

(d)
Fig. 15. Microstructure of boiler quality of steel weldment with FCAW (a) unaffected base metal (b) grain refined HAZ adjacent to unaffected base metal (c) fusion line microstructure (d) fusion zone.

Few microstructures of weldment are also shown. Before placing under microscope, specimens have been etched with 
2\% Nital solution. The base metal microstructure consist predominantly of ferrite and pearlite (Fig. 15(a)). The heat affected zone constitutes of grain refined zone (Fig. 15(b)) adjacent to unaffected base material. Grain-couresd-HAZ reveals martensitic structure (Fig. 15(c)).

\section{F. Conformation Test}

TABLE VIII: CONFIRMATION EXPERIMENTAL RESULTS

\begin{tabular}{|c|c|c|c|c|c|}
\hline & \multicolumn{4}{|c|}{ Optimum welding parameters } & \multirow{3}{*}{$\begin{array}{l}\text { Error } \\
(\%)\end{array}$} \\
\hline & \multirow{2}{*}{\multicolumn{3}{|c|}{$\begin{array}{c}\text { Experimental } \\
G 2 F 2 V 5\end{array}$}} & \multirow{2}{*}{$\begin{array}{c}\text { Prediction } \\
G 2 F 2 V 5 \\
\end{array}$} & \\
\hline Level & & & & & \\
\hline Response & $\begin{array}{l}\text { Value in } \\
\text { used unit }\end{array}$ & GRC & GRD & GRD & \multirow{4}{*}{6.42} \\
\hline $\begin{array}{l}\text { Deposition } \\
\text { rate }\end{array}$ & $0.671 \mathrm{~g} / \mathrm{s}$ & 0.539631 & \multirow{3}{*}{0.691352} & \multirow{3}{*}{0.738756} & \\
\hline $\begin{array}{l}\text { Percentage } \\
\text { of } \\
\text { elongation }\end{array}$ & 33.2 & 0.755656 & & & \\
\hline $\begin{array}{l}\text { Average } \\
\text { FZ } \\
\text { hardness }\end{array}$ & $\begin{array}{c}241.7 \\
\mathrm{HV}\end{array}$ & 0.778768 & & & \\
\hline
\end{tabular}

Within the domain of the experimental range, the optimum parametric condition is found to be $\mathrm{G} 2 \mathrm{~F} 2 \mathrm{~V} 5$ (i.e. gas rate 10 $1 / \mathrm{min}$; wire feed rate $6.74 \mathrm{~m} / \mathrm{min}$ and voltage $26 \mathrm{~V}$ ), in flux cored arc welding of BQ steel of thickness $12 \mathrm{~mm}$. The final step is to conduct the confirmation test. The results of this test are tabulated in Table VIII. At optimized condition the value of GRD is predicted through Taguchi method. The percentage error between confirmation experiment and prediction is 6.42 . It shows that the optimum operating condition agrees fairly with the predicted one.

\section{CONCLUSIONS}

Grey relational grades obtained from the grey relational analysis has been used to optimize the process parameters of FCAW process of boiler quality steel with multiple performance characteristics (deposition rate, percentage of elongation and average hardness of fusion zone) using Taguchi S/N ratio concept on the results of grey relational analysis. The optimization of the complicated multiple performance characteristics is greatly simplified through this approach.

Response surface and contour plots are developed. These are helpful to interpret combined effects of any two parameters on the response(s) while the third parameter is held at some constant level. These plots also help identifying the significance of the interaction effects.

The optimal process parameters predicted in the present analysis are gas flow rate at level $2(10 \mathrm{~m} / \mathrm{min})$, electrode wire feed rate at level $2(6.74 \mathrm{~m} / \mathrm{min})$, and voltage at level 5(36).

Quadratic models for deposition rate, percentage of elongation and average hardness of fusion zone as functions of the process parameters were developed. However the model for deposition rate has been found to be satisfactory. The other models need to be refined by further investigation.

The relative importance among the welding process parameters for the multiple performance characteristics was determined by using ANOVA. The most influencing factor is electrode wire feed rate, next is welding voltage followed by gas flow rate.

\section{REFERENCES}

[1] A. Sadek, R. N. Ibraham, J. W. H. Price, T. Shehata, and M. Ushio, "Effect of welding parameters of FCAW process and shielding gas type on weld bead geometry and hardness distribution," Trans. JWRI, vol 30, no. 2, pp. 45-52, 2001.

[2] P. K. Palani and N. Murugan, "Optimization of weld bead geometry for stainless steel claddings deposited by FCAW," Journal of Materials Processing Technology, vol. 190, pp. 291-299, 2007.

[3] M. T. Liao and W. J. Chen, "A comparison of gas metal arc welding with flux-cored wires and solid wires using shielding Gas," Int. J. Adv. Manuf. Technol., vol. 15, pp. 49-53, 1999.

[4] M. Koçak, "Structural integrity of welded structures: Process, property, performance (3P) relationship," in Proc. 63rd Annual Assembly \& International Conference of the International Institute of Welding, July 11-17, 2010, pp. 3-19.

[5] C. Vidala, V. Infante, P. Peças, and P. Vilaça, "Application of Taguchi method in the optimization of friction stir welding parameters of an aeronautic aluminum alloy," Instituto Superior Técnico, Av. Rovisco, Pais.

[6] U. D. Gulhane, A. B. Dixit, P. V. Bane, and G. S. Salvi, "Optimization of process parameters for 316L stainless steel using Taguchi method and ANOVA," Int. J. of Mechanical Engineering and Technology, vol. 3, no. 2, pp. 67-72, May-August 2012.

[7] B. Arivazhagan, S. Sundaresan, and M. Kamaraj, "Composition on toughness of flux-cored arc weld of modified 9Cr-1Mo (P91) steel," Journal of Materials Processing Technology, pp. 5246-5253, February 2009.

[8] Z. Sterjovski, M. Pitrun, D. Nolan, D. Dunne, and J. Norrish, "Artificial neural networks for predicting diffusible hydrogen content and cracking susceptibility in rutile flux-cored arc welds," Journal of Materials Processing Technology, pp. 420-427, December 2006.

[9] T. Kannan and N. Murugan, "Effect of flux cored arc welding process parameters on duplex stainless steel clad quality," Journal of Materials Processing Technology, vol. 176, no. 3, pp. 230-239, June 2006.

[10] J. Choi and J. Mazumder, "Numerical and experimental analysis for solidification and residual stress in the GMAW process for AISI 304 stainless steel," Journal of Materials Science, vol. 37, pp. 2143-2158, 2002.

[11] H. Hasani, S. A. Tabatabaei, and G. Amiri, "Grey relational analysis to determine the optimum process parameters for open-end spinning yarns," Journal of Engineered Fibers and Fabrics, vol. 7, no. 2, pp. $81-86$

[12] H. Aydin, A. Bayram, U. Esme, Y. Kazancoglu, and O. Guven, "Application of grey relational analysis (GRA) and Taguchi method for the parameters optimization of friction stir welding (FSW) process," Materials and Technology, vol. 44, no. 4, pp. 205-211, 2010.

[13] A. Al-Refaie, L. Al-Durgham, and N. Bata, "Optimal parameter design by regression technique and grey relational analysis," in Proc. the World Congress on Engineering, June 30-July 2, 2010, pp. 1-5.

[14] B. Shivapragash, K. Chandrasekaran, C. Parthasarathy, and M. Samuel, "Multiple response optimizations in drilling using taguchi and grey relational analysis," International Journal of Modern Engineering Research, vol. 3, no. 2, pp. 765-768, March-April 2013.

[15] A. Patnaik, S. Biswas, and S. S. Mahapatra, "An evolutionary approach to parameter optimisation of submerged arc welding in the hard facing process," Int. J. Manufacturing Research, vol. 2, no. 4, pp. 462-483, 2007.

[16] P-value. From Wikipedia, the free encyclopedia. [Online]. Available: http://en.wikipedia.org/wiki/P-value

[17] J. I. Achebo, "Optimization of GMAW protocols and parameters for improving weld strength quality applying the Taguchi method," in Proc. the World Congress on Engineering, London, UK, July 6-8, 2011, vol. 1.

[18] R. V. Lenth, "Response-surface methods in R, using RSM," Journal of Statistical Software, vol. 32, no. 7, pp. 1-17, October 2009.

[19] R. Singh, N. M. Suri, and J. Randhawa, "Optimization of process parameters for TIG welding of 304L stainless steel using response surface Methodology," International Journal of Mechanical Science and Civil Engineering, vol. 2, no. 2, pp. 36-40, June 2013.

[20] Y. Q. Guan, Y. W. Zhang, and L. Zhang, "Optimization for supercritical CO2 extraction of icariin by response surface method," Journal of Chinese Pharmaceutical Sciences, pp. 159-163, 2011. 
[21] S. Datta and S. S. Mahapatra, "Multi-objective optimization of submerged arc welding process," The Journal of Engineering Research, vol. 7, no. 1, pp. 42-52, 2010.

[22] Minitanb. [Online].

Available: http://support.minitab.com/en-us/minitab/17/topic-library/modeling-s tatistics/using-fitted-models/graphs/contour-plots-and-3d-surface-plot

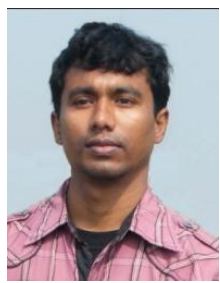

Binoy Krishna Biswas was born on November 24, 1978 at Badkulla, West Bengal, India. He had obtained the B.Tech degree in mechanical engineering, the M.Tech degree in material science and engineering. Presently he is involved in research in welding technology. He is an assistant professor in the Mechanical Engineering Department at B. P. Podda Institute of Management and Technology, India. His research interests include manufacturing (welding, machining) and heat transfer and engineering materials material. He also has published a book titled "Electrical Engineering Materials".

Pradip Kumar Pal was born in Kolkata, India in 1954. He obtained the bachelor of mechanical engineering degree, the master of mechanical engineering degree and the Ph.D. of engineering degree, all from Jadavpur
University, Kolkata, India. He is now holding the post of professor at the same university. His industrial experience is of around 7-8 years, teaching experience of almost 30 years. His research interests include machining, machine tool dynamics, welding and process optimization. He published a good number of papers in international and national journals and conference/seminar proceedings.

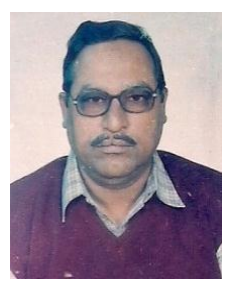

Asish Bandyopadhyay was born in Khardah, India in 1957. He obtained his bachelor of mechanical engineering, master of mechanical engineering and $\mathrm{Ph} . \mathrm{D}$. of Engineering degrees all from Jadavpur University, Kolkata, India. He is now holding the post of professor at the same university. His research interests include manufacturing (welding, machining) and heat transfer. 